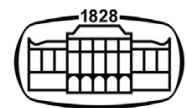

AKADÉMIAI KIADÓ

Journal of Behavioral Addictions

9 (2020) 3, 664-675

DOI:

$10.1556 / 2006.2020 .00068$

(c) 2020 The Author(s)

\title{
The effects of parental control and warmth on problematic internet use in adolescents: A prospective cohort study
}

\author{
KATERINA LUKAVSKÁ ${ }^{1,2 *}$, JAROSLAV VACEK ${ }^{2,3}$ and \\ ROMAN GABHELÍK ${ }^{2,3}$
}

\footnotetext{
${ }^{1}$ Department of Psychology, Faculty of Education, Charles University, Prague, Czech Republic

${ }^{2}$ Department of Addictology, First Faculty of Medicine, Charles University, Prague, Czech Republic

${ }^{3}$ Department of Addictology, General University Hospital in Prague, Prague, Czech Republic
}

Received: February 17, 2020 • Revised manuscript received: June 24, 2020; September 3, 2020 •

Accepted: September 3, 2020

Published online: September 24, 2020

\section{FULL-LENGTH REPORT}

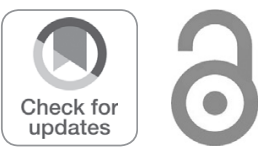

\begin{abstract}
Background and aims: Problematic internet use (PIU) is a highly prevalent condition with severe adverse effects. The literature suggests that parent-child bonding and parental behavioral control exert protective effects against PIU. However, the most relevant studies rely on simplistic measurement of parenting, cross-sectional designs and mixed-aged samples. Our study analyzed the effect of maternal and paternal parenting on PIU by using a prospective design and a cohort sample of same-aged children. Methods: Data from 1,019 Czech 12-year-old sixth-graders who were followed until ninth grade were used. Maternal and paternal responsiveness and strictness were reported by children using the Parental Acceptance-Rejection Questionnaire (PARQ) and the Parental Control Scale (PCS). PIU was measured by the Excessive Internet Use Scale (EIUS). Results: The self-reported PIU prevalence in nine-graders (15-year-old) was $8.1 \%$. Parenting, reported by adolescents 18 months before PIU screening, showed significant relationships with PIU: parental responsiveness was negatively and moderately associated, while maternal strictness showed a weak positive association; the authoritative parenting style in both parents decreased PIU, with a PIU probability of $3.21 \%$, while a combination of maternal authoritarian and paternal neglectful parenting was associated with PIU probability as high as 20.9\%. Discussion and conclusions: The self-reported prevalence of PIU in Czech adolescents was found to be high. The effects of parenting on PIU were similar to the effects of parenting on other problematic behavior among adolescents. Our findings showed the need for interventions to prevent PIU by helping parents to apply optimal parenting styles.
\end{abstract}

\section{KEYWORDS}

adolescence, problematic use of internet, internet addiction, parental control, parental warmth, parenting styles

\section{INTRODUCTION}

With internet access rapidly increasing over the globe (Kuss \& Billieux, 2017), adolescents are currently more online than ever before. The Internet offers many possibilities to learn, socialize, and relax, but it is also associated with risks such as cyberbullying/cybervictimization, exposure to inappropriate content or uncontrollable excessive use (most usually referred to as excessive use of internet (EUI), internet addiction (IA), or problematic internet use (PIU)). PIU, which describes an inability to inhibit online activities despite negative consequences, has an estimated global prevalence of $6.0 \%$ (Cheng \& $\mathrm{Li}, 2014$ ) and is known to have detrimental effects on various aspects of life (Fineberg et al., 2018).

Adolescence is a sensitive period for developing both substance use and behavioral addictions (Balogh, Mayes, \& Potenza, 2013). It has been shown that PIU prevalence is higher among adolescents than in the general population (Kuss, Griffiths, Karila, \& Billieux, 2014). The etiology of PIU seems to be complex, as it includes personality as well as environmental 
factors. There is a growing body of studies focusing on the role of family factors in adolescent PIU.

It seems that a good parent-child relationship is associated with a lower risk of PIU. Casaló \& Escario (2019) found a negative relationship between perceived parental care and excessive internet use in 14- to 18-year-old Spanish adolescents. Having a higher-quality parent-child relationship was found to be negatively associated with PIU in a US sample of 12- to 17-year-olds (Bleakley, Ellithorpe, \& Romer, 2016). Chinese high-school students who reported good relationships (instead of bad relationships) with their fathers were less prone to PIU (Dong et al., 2019). Chinese adolescents (aged 11-18 years) with PIU symptoms reported lower quality of family functioning than those without PIU (Shi, Wang, \& Zou, 2017). Shanghai adolescents (11-20 years) with worse relationships with mothers or fathers showed higher PIU scores (Xu et al., 2014). A small negative correlation between the quality of the parent-child relationship and PIU was found in Hong Kong adolescents aged 13 years (Shek, Zhu, \& Ma, 2018) and 16 years (Shek, Zhu, \& Dou, 2019). The only study using data from parents rather than children found a moderate negative association between PIU and parental care but a moderate positive association between PIU and parental overprotection (Siomos et al., 2012). Finally, Chinese adolescents with clinically diagnosed PIU reported lower paternal and maternal emotional warmth and higher rejection and overinvolvement when compared to healthy controls (Xiuqin et al., 2010).

In the case of parental control, the results are less clear. The variability in concepts and measures of parental control is high. Some studies differentiate between behavioral control (monitoring and taking interest in children's activities, modeling appropriate behavior and setting regulative rules) and psychological control (negative parenting practice that includes trying to make children emotionally dependent on a parent using strategies such as guilt induction and love withdrawal). While psychological control is well known to have adverse effects on many aspects of children's development (Siomos et al., 2012), it is not surprising that it has been shown to be positively correlated with PIU (Cetinkaya, 2019; Li, Li, \& Newman, 2013; Shek, Zhu, \& Dou, 2019; Shek, Zhu, \& Ma, 2018). Findings on the relationship between behavioral control and PIU have included a small negative association for both parents (Shek, Zhu, \& Ma, 2018), a small negative association significant only for paternal (not maternal) control (Shek et al., 2019), a small protective effect that was fully mediated by the child's selfcontrol (Li et al., 2013), and a small negative nonsignificant association (Cetinkaya, 2019). Regarding the effect of concepts similar to parental behavioral control, Casaló \& Escario (2019) found a small negative association between setting regulatory rules and excessive use of the internet, but only in girls. Dong et al. (2019) and Wu et al. (2016) demonstrated the lowest PIU prevalence in a group of adolescents reporting an average level of parental control (compared to "little" and "much"). However, in these two studies, the degree of parental control was measured by a single item. It seems that parental behavioral control can prevent PIU, but its simplistic measurement seriously limits conclusions that may be inferred from currently available research. In related research areas, such as adolescents' substance use, more elaborate measures of parenting can be found. Calafat, García, Juan, Becoña, and Fernández-Hermida (2014), using a two-dimensional conceptualization of parental behavior consisting of responsiveness (warmth, acceptance, involvement) and strictness (control, demandingness, imposition, parental firmness), showed that parenting styles with high responsiveness (indulgent and authoritative parenting styles) are more protective against adolescent substance than styles with low responsiveness (authoritarian and neglectful parenting styles).

The abovementioned studies analyzing the effects of parents on adolescent PIU have limitations. Most studies relied on simple methods to measure parental control, and only a few distinguished between maternal and paternal parenting. In addition, most studies used a cross-sectional design, which does not allow for an estimation of the longterm effect of parental behavior on PIU.

In the current study, we address all these limitations. Our aim was to analyze how adolescent PIU was influenced by parental behavior (both maternal and paternal) as measured by a reliable and valid instrument that distinguishes between responsiveness and strictness.

\section{METHODS}

\section{Setting}

This study utilized data from a project evaluating prevention intervention aimed at substance use in school children. This project took place in schools representing four regions in Czechia between 2013 and 2017. The units of data collection were 6th grade classes (children aged 11-13 years) from participating schools. A total of 3,017 children who attended these classes and their parents were asked to participate in the project. For more details on the project, see Gabrhelík et al. (2014).

\section{Data collection}

The first wave (out of seven waves) of data collection in children took place in the fall of 2013 (mean age of children: $11.9, \mathrm{SD}=0.41, N=1,000)$. The following six waves of data collection in children were in spring and fall of each year, i.e., at the beginning and end of a school year. The last wave took place in spring 2017 in the ninth grade. A web-based questionnaire was used to collect data from the children. We used data from parents collected between waves 1 and 2 (Fig. 1). The mean age of the parents was $40.9, \mathrm{SD}=4.72$, $N=1,011$. Parents were asked to fill in questionnaires in a pen-and-paper format.

\section{Sample}

We analyzed data from a subset of children and their parents participating in the project described earlier. The inclusion 


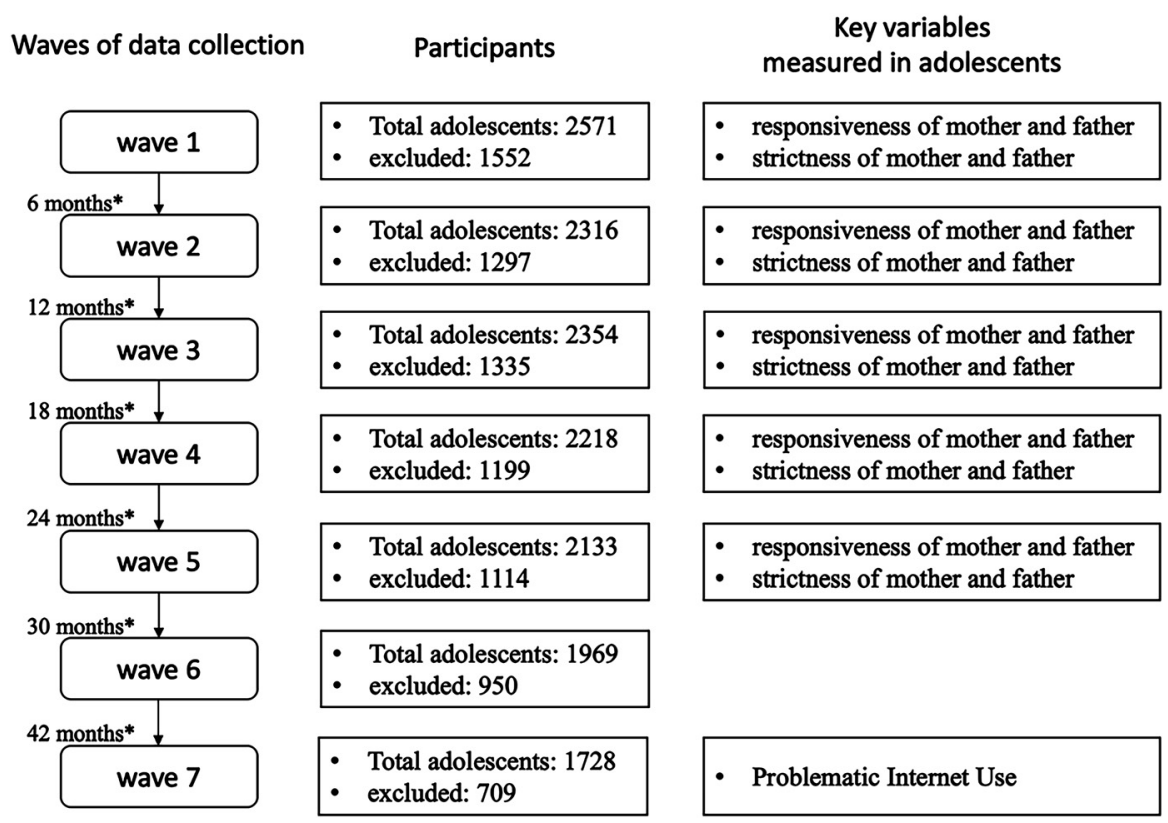

Fig. 1. The timeline of data collection, flow of participants between waves and variables of interest for the presented study $(N=1,019$ childparent dyads in all waves).

Note. Data from parents were collected only at baseline (between wave 1 and 2). 1931 parents (83\% mothers) participated, 912 were excluded. Wave 1 and 2 took place when adolescents were in 6th grade, wave 3 and 4 when they were in 7 th grade, wave 5 and 6 when they were in 8 th grade and wave 7 when they were in 9th grade.

${ }^{*}$ Time from wave 1 .

criteria for adolescents were as follows: (1) provided data regarding PIU (wave 7), (2) provided data on parental responsiveness and strictness for both parents (mothers and fathers) in at least three waves (1-5), and (3) provided a valid identification code that could be matched with a parental code. The inclusion criteria for parents were as follows: (1) completed parental questionnaires before the start of the second wave of data collection in children, and (2) provided a valid parental self-generated identification code (SGIC) that could be matched with the child's SGIC (Vacek, Vonkova, \& Gabrhelík, 2017). A total of 2,810 children out of 3,017 eligible children (93.14\%) participated in at least one wave of data collection (not necessarily in the first wave). First, we excluded 997 children who could not be paired with their parent; second, we excluded 77 children with nonvalid answers (i.e., those who reported the use of the made-up substance called "Semeron" in any wave); third, we excluded 604 children who did not provide valid measurements of the outcome variable (PIU, wave 7); and fourth, we excluded 113 children who did not provide valid responses for the main predicting variables (responsiveness and strictness of mother and father) in at least three waves. A total of 1,019 children met all inclusion criteria. Among 3,017 eligible parents, 1,931 parents $(68.7 \%)$ completed the parental questionnaire. A total of 118 parents were excluded because they could not be matched with the child (i.e., either a child or a parent did not provide valid SGIC). Another 794 parents were excluded because their child did not meet the inclusion criteria and was excluded. The final sample consisted of 1,019 child-parent dyads that met all inclusion criteria. The characteristics of the final sample are shown in Table 1.

\section{Missing data}

Missing values in the main predicting variables (parental behavior) were imputed using the multiple imputation (MI) method (Honaker, King, \& Blackwell, 2011). The total amount of imputed data was $9.35 \%$, which was acceptable (Twisk \& de Vente, 2002). We did not impute any data in the outcome variable (PIU), and we also did not impute variables measured by one item and/or in one wave (e.g., adolescent's gender, family intactness, family income, and parental education).

\section{Measures}

We used a Web-based questionnaire for collecting data from the children; their parents were asked to fill in questionnaires in a pen-and-paper version. Anonymous SGICs were used to allow the baseline questionnaire data collected from the children to be linked to data from their parents (Vacek et al., 2017).

Predicting variables - Parental responsiveness (warmth) and strictness (control). Parental responsiveness and strictness were reported by children using the Warmth/ Affection subscale (WAS) from the Parental AcceptanceRejection Questionnaire (PARQ) (Rohner, Khaleque, \& Cournoyer, 2005) and the Parental Control Scale (PCS) (Rohner \& Khaleque, 2003). Both scales proved to be reliable measures of parental behavior in various contexts and cultures, including the Czech Republic (Becoña et al., 2012; 
Table 1. The characteristics of sample $(N=1,019)$

\begin{tabular}{|c|c|c|c|}
\hline & & $N$ & $\begin{array}{c}\text { Percentage } \\
(\%)\end{array}$ \\
\hline \multirow[t]{3}{*}{ Gender of adolescent } & Girl & 522 & 51 \\
\hline & Boy & 480 & 47 \\
\hline & Missing & 17 & 2 \\
\hline \multirow[t]{3}{*}{ Gender of parent ${ }^{\mathrm{a}}$} & Female & 843 & 83 \\
\hline & Male & 170 & 17 \\
\hline & Missing & 6 & 1 \\
\hline \multirow[t]{4}{*}{ Family intactness ${ }^{\mathrm{a}}$} & Intact & 832 & 82 \\
\hline & Restructured & 65 & 6 \\
\hline & Incomplete & 120 & 12 \\
\hline & Missing & 2 & 0 \\
\hline \multirow[t]{9}{*}{ Family income $^{a}$} & Less than 600 EUR & 35 & 3 \\
\hline & 600-800 EUR & 61 & 6 \\
\hline & 800-1,000 EUR & 97 & 10 \\
\hline & 1,000-1,200 EUR & 134 & 13 \\
\hline & 1,200-1,600 EUR & 251 & 25 \\
\hline & 1,600-2,400 EUR & 191 & 19 \\
\hline & 2,400-3,200 EUR & 77 & 8 \\
\hline & More than 3,200 EUR & 46 & 5 \\
\hline & Missing & 127 & 12 \\
\hline \multirow[t]{6}{*}{ Education of mother } & Elementary & 43 & 4 \\
\hline & Practical & 135 & 13 \\
\hline & High school & 258 & 25 \\
\hline & Incomplete further education & 39 & 4 \\
\hline & Completed further education & 249 & 24 \\
\hline & Missing & 295 & 29 \\
\hline \multirow[t]{6}{*}{ Education of father } & Elementary & 36 & 4 \\
\hline & Practical & 153 & 15 \\
\hline & High school & 215 & 21 \\
\hline & Incomplete further education & 40 & 4 \\
\hline & Completed further education & 260 & 26 \\
\hline & Missing & 315 & 31 \\
\hline
\end{tabular}

${ }^{a}$ Reported by a parent.

Cablova, Csemy, Belacek, \& Miovsky, 2016; Khaleque \& Rohner, 2012; Rohner \& Khaleque, 2003).

The PCS assessed the child's perception of parental behavioral control. It included 13 items describing parental regulative behavior, such as monitoring children's whereabouts and activities, setting rules, and limiting children's freedom (e.g., "My mother tells me exactly what time to be home when I go out"). The shortened PARQ-WAS inventory consisted of eight items describing responsiveness and affection toward the child - expressing interest and positive feelings toward the child, praising the child's opinion, etc. (e.g., "My mother talks to me about our plans and listens to what I have to say"). In both scales, there were two identical sets of items for maternal and paternal behavior. The respondents evaluated how often the described behavior was true for his/her mother or father on a 1 to 4 scale, where 4 meant "always true" and 1 means "never true" (except for a few items that were reversely coded).

We computed four scores for each participant: maternal strictness, paternal strictness, maternal responsiveness, and paternal responsiveness as average scores on the PCS and PARQ-WAS items. Furthermore, following the procedure by Calafat et al. (2014) and others, we identified the four parenting styles of mothers and fathers based on their combination of strictness and responsiveness scores: authoritative (high responsiveness and high strictness), authoritarian (low responsiveness and high strictness), indulgent (high responsiveness and low strictness), or neglectful (low responsiveness and low strictness). High/low categorization was based on the median (50th percentile) split.

Outcome variable - Problematic internet use. PIU was measured by the Excessive Internet Use Scale (EIUS) (Šmahel, Vondráčková, Blinka, \& Godoy-Etcheverry, 2009). The EIUS is a 10 -item scale evaluating 5 symptoms of PIU: cognitive and behavioral salience, tolerance, withdrawal, conflicts, and problems with limiting time online (i.e., loss of control). Each symptom is measured by two questions on a 4 -point Likert scale ( 1 - never to 4 - very often). A symptom is present if the respondent answered "often" or "very often" to at least one question assessing the symptom. PIU is present if conflict and at least three other symptoms are present (that means that one symptom, excluding conflict, can be missing). The EIUS is widely used in the European context (Škařupová, Ólafsson, \& Blinka, 2015). The items were extended to ensure that adolescents would include gaming in their online activities (e.g., "Does it happen to you 
that you stay online or were gaming for longer time than originally planned?"). This was done to aid adolescents in understanding that internet use included not only browsing the web and using social media, but also gaming. According to the standard procedure (Šmahel et al., 2009), we calculated the PIU score as a sum of positive symptoms (0-5) and determined the PIU status as a nominal variable reflecting whether the participant fulfilled the criteria of PIU (i.e., scored positive in conflict symptoms and at least three of the other four symptoms measured by the EIUS) or not.

Sociodemographic background variables. The number of sociodemographic characteristics was reported by adolescents (age, gender, school grades, family intactness and educational level of mother and father) or by parents (family income, parents' age).

\section{Statistical analysis}

The prevalence of PIU was established, and the effect of sociodemographic variables on PIU was examined using the $\chi^{2}$ test of association (adolescent's gender, family intactness, family income, educational level of mother, educational level of father) or by Welch's $t$-test (adolescent's school grades).

We analyzed the differences between maternal and paternal behavior using paired $t$-tests, and we analyzed the development of parental strictness and responsiveness over time using repeated measures ANOVA with Bonferroni post hoc tests. We also examined associations between parenting styles and sociodemographic variables by the $\chi^{2}$ test of association and Welch's $t$-test.

The effects of parental behavior on adolescent IA were analyzed in several steps. First, we computed correlations between the PIU score (wave 7) and maternal and paternal responsiveness and strictness (wave 1-5). Second, we compared maternal and paternal responsiveness and strictness scores in adolescents with and without PIU. Finally, we assessed the combined effect of responsiveness and strictness by using the parenting styles (wave 5) that reflect different combinations of responsiveness and strictness. We examined the incidence of PIU according to parenting styles by the $\chi^{2}$ test of association and then computed the probability of adolescent PIU in groups with various combinations of maternal and paternal parenting styles using logistic regression.

\section{Ethics}

The study was approved by the Ethical Committee of the General University Hospital in Prague. All subjects were informed about the study, and all provided informed consent. Parental consent was obtained for those younger than 18 years of age.

\section{RESULTS}

\section{PIU prevalence and the effect of sociodemographic variables on PIU}

The prevalence of self-reported PIU in our sample was $8.1 \%$. The PIU score ranged between 0 and $5(M=1.36, \mathrm{MD}=1$,
SD $=1.49)$. The prevalence was slightly higher in boys $(9.2 \%)$ than in girls $(7.3 \%)$, but the association between gender and PIU status was not significant $\left(\chi^{2}=1.18, P=\right.$ $0.276, N=1,002)$. However, the PIU score (the sum of positive symptoms) was significantly higher in boys $(M=$ $1.50, \mathrm{SD}=1.52)$ than in girls $(M=1.24, \mathrm{SD}=1.46)$ with $\mathrm{MD}=0.266$, Welch's $t(986)=2.82, P=0.005$, and Cohen's $d=0.179$.

None of the other examined sociodemographic variables were significantly associated with PIU status, namely, family income $\left(\chi^{2}(7)=4.85, P=0.678, N=892\right)$, family intactness $\left(\chi^{2}(2)=3.02, P=0.221 . N=1,017\right)$, education of mother $\left(\chi^{2}(4)=2.58, P=0.630, N=724\right)$, education of father $\left(\chi^{2}(4)=2.37, P=0.668, N=704\right)$ and parental age $(t(85.6)=0.481, P=0.632, N=1,002)$.

School grades were worse in the PIU group $(M=2.10$, $\mathrm{SD}=1.93)$ than in the group without PIU $(M=1.8, \mathrm{SD}=$ $1.15)$. The difference was not statistically significant (Welch's $t(83.8)=-1.38, P=0.171)$, but there was a moderate effect size (Cohen's $d=-0.247$ ).

\section{Parental behavior}

Adolescents' reports on the responsiveness and strictness of their mothers and fathers showed high stability within a two-year period. The between-waves Pearson's correlations for responsiveness and strictness ranged from 0.417 to 0.721 .

As shown in Table 2, adolescents in all waves reported significantly higher maternal responsiveness (Student's paired-sample $t$ 's ranged from 9.02 to 11.24 , all $P$ 's $<0.001$, Cohen's $d$ between 0.282 and 0.352 ) and strictness ( $t$ between 9.77 and 11.53, all $P$ 's $<0.001$, Cohen's $d$ between 0.306 and 0.361 ) than paternal responsiveness and strictness. Reports on maternal and paternal behavior were strongly correlated both for responsiveness (Pearson's $r$ ranged from 0.539 to 0.593 , all $P^{\prime} s<0.001$ ) and strictness (Pearson's $r$ ranged from 0.447 to 0.556 , all $P^{\prime} s<0.001$ ).

While analyzing the development of parental behavior over time (Table 2, Figs. 2-3), we found significant betweenwave differences in maternal responsiveness $(F(4)=16.0$, $P<0.001$ ), with significant Bonferroni post hoc tests between early waves (1-3) and late waves (4-5) (all $P<0.001$, Cohen's $d$ between 0.10 and 0.20 ). A similar pattern was found for paternal responsiveness - scores were higher in early waves (1-3) than in late waves (4-5). Between-wave differences in paternal responsiveness were significant $(F(4)$ $=9.55, P<0.001)$, but only some post hoc comparisons were significant (namely, wave 1 versus wave $4-5$; wave 5 versus wave $2-3$, all $P<0.001$, Cohen $d$ 's between 0.10 and $0.15)$. The differences between early and late waves were even more pronounced in the case of strictness. In maternal strictness, the between-wave differences were significant $(F(4)=67.2, P<0.001)$, with all post hoc tests significant (all $P$ 's $<0.001$, Cohen $d$ 's between 0.11 and 0.36) except two: wave 1 versus 2 and wave 4 versus 5 . In paternal strictness, the differences were also significant $(F(4)=43.2$, $P<0.001$ ) with all significant post hoc tests (all $P$ 's $<0.001$, Cohen $d$ 's between 0.12 and 0.30 ), except wave 2 versus 3 and wave 4 versus 5 . 
Table 2. Maternal and paternal responsiveness and strictness as measured in waves 1-5, their correlations with each other (maternal-paternal), correlations with PIU (wave 7), and differences between maternal and paternal variables. $(N=1,019)$

\begin{tabular}{|c|c|c|c|c|c|c|}
\hline \multirow[b]{2}{*}{ Variable } & \multicolumn{2}{|c|}{ Maternal } & \multicolumn{2}{|c|}{ Paternal } & \multicolumn{2}{|c|}{ Maternal-Paternal } \\
\hline & Mean (SD) & $\begin{array}{l}\text { Correlation with PIU } \\
\text { (wave 7)-Pearson } r\end{array}$ & Mean (SD) & $\begin{array}{l}\text { Correlation with PIU } \\
\text { (wave 7)-Pearson } r\end{array}$ & $\begin{array}{c}\text { Difference-Student } \\
t^{\mathrm{a}}(\text { Cohen } d)\end{array}$ & Correlation-Pearson \\
\hline Responsiveness - wave 1 & $3.51(0.472)$ & $-0.110^{* * *}$ & $3.35(0.615)$ & $-0.101^{* *}$ & $10.10^{* * *}(0.316)$ & $0.583^{* * *}$ \\
\hline Responsiveness - wave 2 & $3.54(0.527)$ & $-0.152^{* * \star}$ & $3.33(0.686)$ & $-0.129^{* * \star}$ & $11.10^{* * *}(0.348)$ & $0.557^{* * *}$ \\
\hline Responsiveness - wave 3 & $3.52(0.522)$ & $-0.101^{* *}$ & $3.33(0.675)$ & $-0.092^{* *}$ & $11.24^{* * *}(0.352)$ & $0.593^{* * *}$ \\
\hline Responsiveness - wave 4 & $3.46(0.598)$ & $-0.128^{* * *}$ & $3.28(0.695)$ & $-0.147^{* * *}$ & $9.02^{* * *}(0.282)$ & $0.542^{* * *}$ \\
\hline Responsiveness - wave 5 & $3.43(0.596)$ & $-0.120^{* * *}$ & $3.25(0.706)$ & $-0.127^{* * *}$ & $9.30^{* * *}(0.291)$ & $0.539^{* * *}$ \\
\hline Strictness - wave 1 & $3.00(0.374)$ & -0.006 & $2.86(0.475)$ & -0.008 & $11.39^{* * *}(0.357)$ & $0.560^{* * *}$ \\
\hline Strictness - wave 2 & $2.98(0.392)$ & 0.037 & $2.82(0.493)$ & 0.004 & $11.53^{* * *}(0.361)$ & $0.488^{* * *}$ \\
\hline Strictness - wave 3 & $2.95(0.391)$ & 0.004 & $2.81(0.501)$ & 0.005 & $10.47^{* * *}(0.328)$ & $0.566^{* * *}$ \\
\hline Strictness - wave 4 & $2.87(0.412)$ & 0.018 & $2.71(0.530)$ & -0.033 & $10.00^{* * *}(0.313)$ & $0.483^{* * *}$ \\
\hline Strictness - wave 5 & $2.86(0.406)$ & 0.040 & $2.71(0.504)$ & -0.029 & $9.77^{* * *}(0.306)$ & $0.402^{* * *}$ \\
\hline
\end{tabular}

${ }^{* *} P<0.01,{ }^{* * *} P<0.001$.

${ }^{a} d f=1,018$ for all analyses.
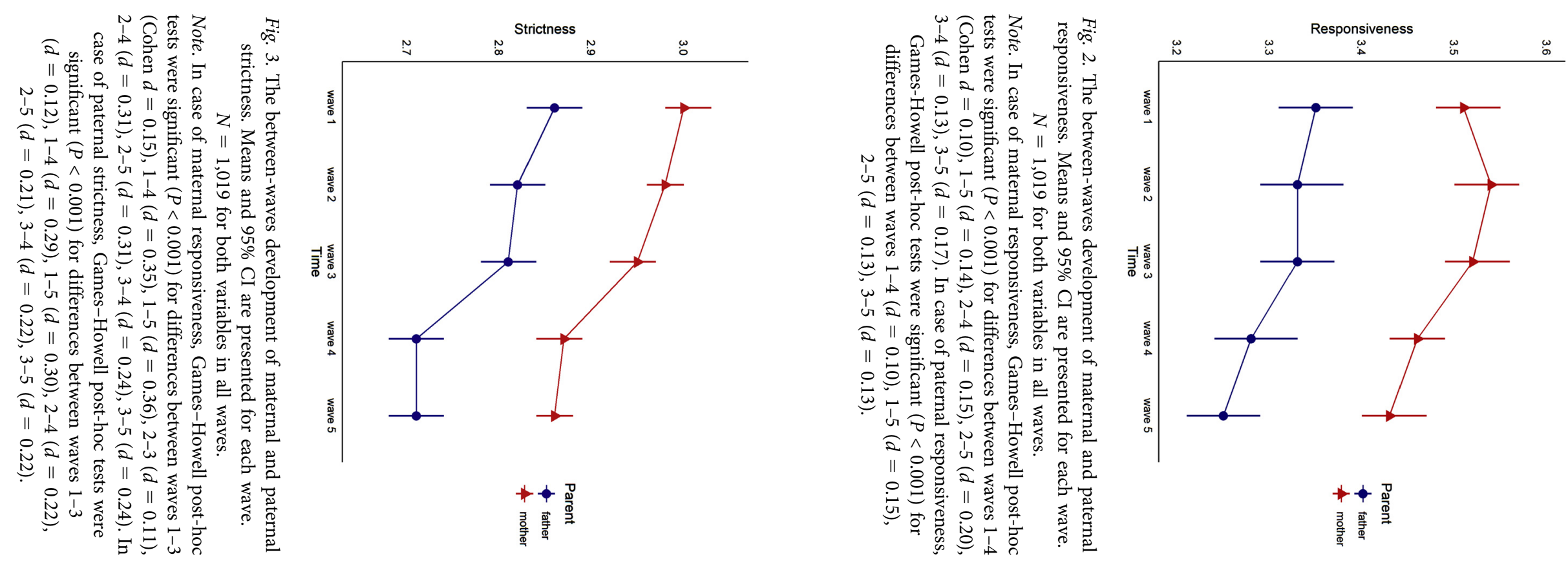
Table 3. Means, standard deviations (SDs) and mean differences for parental responsiveness and strictness (wave 5) in adolescents with selfreported PIU and without PIU (wave 7)

\begin{tabular}{lccc}
\hline Variable & PIU $(n=83)$ & $\begin{array}{c}\text { without PIU }(n=936) \\
\text { Mean (SD) }\end{array}$ & $\begin{array}{c}\text { Difference - Welch } t \\
(\text { Cohen } d)\end{array}$ \\
\hline Maternal responsiveness - wave 5 & $3.24(0.665)$ & $3.45(0.587)$ & $2.74^{* *}(0.349)$ \\
Paternal responsiveness - wave 5 & $3.05(0.723)$ & $3.27(0.702)$ & $2.68^{* *}(0.315)$ \\
Maternal strictness - wave 5 & $2.94(0.394)$ & $2.85(0.406)$ & $-2.02^{*}(-0.226)$ \\
Paternal strictness - wave 5 & $2.64(0.547)$ & $2.72(0.500)$ & $1.17(0.144)$ \\
\hline
\end{tabular}

${ }^{*} P<0.05,{ }^{* *} P<0.01$.

Table 4. Crosstabulation of parenting style of mother (wave 5) and PIU status (wave 7)

\begin{tabular}{|c|c|c|c|c|}
\hline \multirow[b]{2}{*}{ Maternal parenting style } & & \multicolumn{2}{|c|}{ PIU status } & \multirow[b]{2}{*}{ Total } \\
\hline & & PIU $(n=83)$ & $\begin{array}{c}\text { without } \\
\text { PIU }(n=936)\end{array}$ & \\
\hline \multirow[t]{3}{*}{ Authoritative } & Observed & 10 & 215 & 225 \\
\hline & Expected & 18.3 & 207 & \\
\hline & $\%$ of PIU & 4.4 & & \\
\hline \multirow[t]{3}{*}{ Indulgent } & Observed & 15 & 206 & 221 \\
\hline & Expected & 18.0 & 203 & \\
\hline & $\%$ of PIU & 6.8 & & \\
\hline \multirow[t]{3}{*}{ Authoritarian } & Observed & 39 & 231 & 270 \\
\hline & Expected & 22.0 & 248 & \\
\hline & $\%$ of PIU & 14.4 & & \\
\hline \multirow[t]{3}{*}{ Neglectful } & Observed & 19 & 284 & 303 \\
\hline & Expected & 24.7 & 278 & \\
\hline & $\%$ of PIU & 6.3 & & \\
\hline
\end{tabular}

Note. "Observed" shows the observed number of participants with and without PIU in each category of maternal parenting. "Expected" shows the estimated number of participants based on the null hypothesis (i.e., incidence of PIU is not associated with maternal style). "\% of PIU" shows the percentage of participants with PIU in each category of maternal parenting.

Parenting styles. The parenting styles (as measured in wave 5) were associated with adolescents' gender for both maternal style $\left(\chi^{2}(3)=17.3, P=0.001, N=1,002\right)$ and paternal style $\left(\chi^{2}(3)=26.2, P<0.001, N=1,002\right)$. For maternal parenting, boys, compared to girls, reported a higher incidence of neglectful parenting (33.1\% versus $26.6 \%$ of girls) and a lower incidence of indulgent parenting (16.3\% versus $26.8 \%$ of girls). Similarly, for paternal parenting, boys reported a lower incidence of indulgent parenting (16.3\% versus $27.6 \%$ of girls) and a higher incidence of authoritative parenting (29.6\% versus $19.5 \%$ of girls).

The parenting style of the mother was also affected by the intactness of the family $\left(\chi^{2}(6)=13.5, P=0.036, N=\right.$ $1,017)$. Adolescents from restructured families showed a higher incidence of authoritarian parenting (37.7\% versus $22.1 \%$ of intact and $17.5 \%$ of incomplete families) and a lower incidence of indulgent parenting (16.9\% versus $25.6 \%$ of intact and $30.0 \%$ of incomplete families).

\section{Associations between parental behavior and PIU}

As presumed, we found significant negative correlations between PIU score and both maternal and paternal responsiveness in all five waves (Table 2). Surprisingly, we did not find any significant correlations between PIU score and maternal or paternal strictness as measured either in proximate or distant waves (Table 2).

Adolescents with PIU $(N=83)$ also reported significantly lower scores in maternal responsiveness and paternal responsiveness and significantly higher scores in maternal strictness when compared to adolescents without PIU ( $N=$ 936) (Table 3). The difference between adolescents with PIU and without PIU in paternal strictness was not significant.

The effect of parenting styles on PIU. We found a significant association between PIU status and both maternal parenting style $\left(\chi^{2}(3)=20.4, P<0.001, N=1,019\right)$ and paternal parenting style $\left(\chi^{2}(3)=10.6, P=0.014, N=\right.$ $1,019)$. The incidence of PIU was relatively higher in adolescents who reported maternal authoritarian parenting (Table 4) and a paternal neglectful parenting (Table 5). In mothers as well as in fathers, the authoritative parenting style was associated with the lowest incidence of adolescent PIU.

The logistic regression assessing the mutual effect of maternal and paternal parenting styles on PIU showed that both predictors significantly affected PIU status, although they explained only a small proportion of the variability in PIU status $(4.87 \%)$. In both mothers and fathers, the authoritative parenting style (high responsiveness, high 
Table 5. Crosstabulation of parenting style of father (wave 5) and PIU status (wave 7)

\begin{tabular}{|c|c|c|c|c|}
\hline \multirow[b]{2}{*}{ Paternal parenting style } & & \multicolumn{2}{|c|}{ PIU status } & \multirow[b]{2}{*}{ Total } \\
\hline & & $\operatorname{PIU}(n=83)$ & without PIU $(n=936)$ & \\
\hline \multirow[t]{3}{*}{ Authoritative } & Observed & 11 & 240 & 251 \\
\hline & Expected & 20.4 & 231 & \\
\hline & $\%$ of PIU & 4.4 & & \\
\hline \multirow[t]{3}{*}{ Indulgent } & Observed & 15 & 208 & 223 \\
\hline & Expected & 18.2 & 205 & \\
\hline & $\%$ of PIU & 6.7 & & \\
\hline \multirow[t]{3}{*}{ Authoritarian } & Observed & 21 & 215 & 236 \\
\hline & Expected & 19.2 & 217 & \\
\hline & $\%$ of PIU & 8.9 & & \\
\hline \multirow[t]{3}{*}{ Neglectful } & Observed & 36 & 273 & 309 \\
\hline & Expected & 25.2 & 284 & \\
\hline & $\%$ of PIU & 11.7 & & \\
\hline
\end{tabular}

Note. "Observed" shows the observed number of participants with and without PIU in each category of paternal parenting. "Expected" shows the estimated number of participants based on the null hypothesis (i.e., incidence of PIU is not associated with paternal style). "\% of PIU" shows the percentage of participants with PIU in each category of paternal parenting.

Table 6. Model Coefficients with Maternal parenting style (wave 5) and Paternal parenting style (wave 5) as predictors and PIU (wave 7) as outcome. $N=1,019$, Adjusted $r^{2}=0.0487$

\begin{tabular}{|c|c|c|c|c|c|}
\hline \multirow[b]{2}{*}{ Predictor } & \multirow[b]{2}{*}{$B$} & \multirow[b]{2}{*}{ SE $B$} & \multirow[b]{2}{*}{ Odds ratio } & \multicolumn{2}{|c|}{$95 \% \mathrm{CI}$} \\
\hline & & & & Lower & Upper \\
\hline \multicolumn{6}{|c|}{ Maternal parenting style } \\
\hline Indulgent & 0.238 & 0.435 & 1.2685 & 0.5408 & 2.9752 \\
\hline Authoritarian & $1.007^{*}$ & 0.393 & 2.7374 & 1.2671 & 5.9140 \\
\hline Neglectful & -0.129 & 0.438 & 0.8790 & 0.3725 & 2.0744 \\
\hline \multicolumn{6}{|c|}{ Paternal parenting style } \\
\hline Indulgent & 0.530 & 0.425 & 1.6995 & 0.7385 & 3.9113 \\
\hline Authoritarian & 0.487 & 0.406 & 1.6282 & 0.7350 & 3.6068 \\
\hline Neglectful & $1.067^{* *}$ & 0.386 & 2.9062 & 1.3644 & 6.1901 \\
\hline
\end{tabular}

Note. $B$ represents the log odds of "PIU $=1$ " versus "PIU $=0$ (i.e., without PIU)". CI = confidence interval of Odds ratio. Authoritative parenting style of both mother and father is the reference category.

${ }^{*} P<0.05,{ }^{* *} P<0.01$

strictness) led to the lowest probability of PIU. In contrast, in mothers the authoritarian parenting style and in fathers the neglectful parenting style led to a significantly higher probabilities of developing PIU than the authoritative parenting style (Table 6). The combination of maternal and paternal authoritative styles, which also was quite prevalent (11.7\% of adolescents reported this combination) seemed to be protective against PIU with a probability of PIU equal to $3.21 \%$. The most problematic combination - maternal authoritarian parenting combined with paternal neglectful parenting - showed a $20.9 \%$ probability of PIU (Table 7 , Fig. 4).

All variables that were found to be significantly related to PIU or parenting styles (i.e., school grades, adolescent gender, and family intactness) were gradually included in the model to control for their possible interactions with predictors. None of these background variables significantly improved the predictive power of the model and were excluded from the final model.

\section{DISCUSSION}

The self-reported prevalence of PIU was $8.1 \%$ for the whole sample. Background variables (adolescent's gender, family income, parent's education, family intactness) did not affect PIU status. Adolescents reported higher scores of responsiveness and strictness for mothers than for fathers. Differences were significant and with moderate effect sizes. The perception of responsiveness and strictness constantly decreased as adolescents became older with a remarkable decrease at approximately 13.5 years of age. Most differences in responsiveness between early waves (1-3) and late waves (4-5) were significant but with small effect sizes. In the case of strictness, the differences between early and late waves were significant and had small to moderate effect sizes. Adolescents with PIU symptomatology reported significantly lower maternal and paternal responsiveness and higher maternal strictness when compared to the group without PIU. Effect sizes of differences were moderate in 
Table 7. Estimated marginal means of PIU probability (wave 7) for maternal and paternal parenting styles (wave 5 ). $N=1,019$

\begin{tabular}{lccccc}
\hline & & & & \multicolumn{2}{c}{$95 \%$ Confidence interval } \\
\cline { 5 - 6 } Paternal & Maternal & Probability $(\%)$ & SE & Lower & Upper \\
\hline Authoritative & Authoritative $(N=119)$ & 3.21 & 0.0121 & 0.0152 & 0.0666 \\
& Indulgent $(N=52)$ & 4.04 & 0.0160 & 0.0184 & 0.0864 \\
& Authoritarian $(N=51)$ & 8.33 & 0.0275 & 0.0429 & 0.1556 \\
Indulgent & Neglectful $(N=29)$ & 2.84 & 0.0116 & 0.0127 & 0.0623 \\
& Authoritative $(N=53)$ & 5.34 & 0.0207 & 0.0247 & 0.1118 \\
& Indulgent $(N=114)$ & 6.68 & 0.0195 & 0.0373 & 0.1169 \\
& Authoritarian $(N=22)$ & 13.38 & 0.0413 & 0.0714 & 0.2370 \\
Authoritariannyyyyy & Neglectful $(N=34)$ & 4.73 & 0.0177 & 0.0224 & 0.0969 \\
& Authoritative $(N=36)$ & 5.13 & 0.0201 & 0.0235 & 0.1084 \\
& Indulgent $(N=16)$ & 6.42 & 0.0237 & 0.0307 & 0.1293 \\
Neglectful & Authoritarian $(N=117)$ & 12.89 & 0.0273 & 0.0842 & 0.1925 \\
& Neglectful $(N=67)$ & 4.54 & 0.0147 & 0.0238 & 0.0846 \\
& Authoritative $(N=17)$ & 8.80 & 0.0322 & 0.0421 & 0.1750 \\
& Indulgent $(N=39)$ & 10.91 & 0.0337 & 0.0584 & 0.1947 \\
& Authoritarian $(N=80)$ & 20.90 & 0.0387 & 0.1431 & 0.2949 \\
& Neglectful $(N=173)$ & 7.82 & 0.0180 & 0.0495 & 0.1215 \\
\hline
\end{tabular}

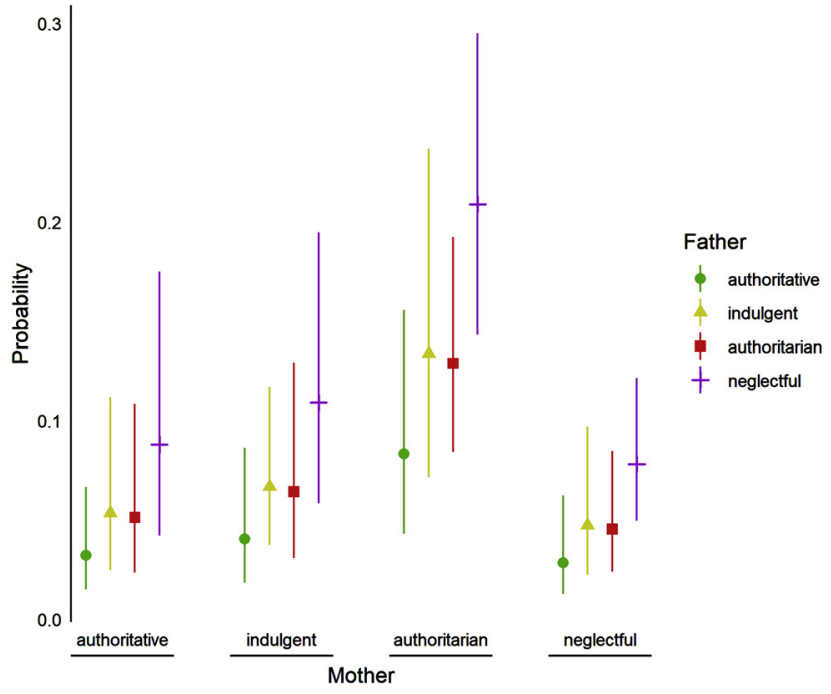

Fig. 4. The probability of PIU (wave 7) in groups with various combinations of maternal and paternal parenting styles (wave 5). The probabilities and 95\% CI are presented for each group.

cases of responsiveness (both maternal and paternal) and small in cases of strictness. For both maternal and paternal parenting, the authoritative style (high responsiveness and high strictness) had the lowest PIU prevalence. The subsequent logistic regression assessing the parenting style of both parents together showed that the combination maternal and paternal authoritative parenting styles was linked to the low prevalence of adolescent PIU (3.21\%). The highest PIU prevalence was found in children with a combination of maternal authoritarian and paternal neglectful parenting styles (20.9\%).

The prevalence of PIU in the Czech Republic could be considered high. In Northern and Western Europe, the 2014 prevalence was approximately $2.6 \%$ (Cheng \& Li, 2014). The higher prevalence was reported from the Middle East, with estimates of approximately $10.9 \%$ (Cheng \& Li, 2014). To the best of our knowledge, no recent data have been published that indicate the prevalence of adolescent PIU in the Czech Republic or Central Europe (Kuss et al., 2014), except for data from Hungary, where a few studies on representative samples of adolescents were recently conducted. Demetrovics et al. (2016), when validating the short form of the PIU Questionnaire, identified $14.44 \%$ of 16 -year-old adolescents as being at risk of PIU. Bányai et al. (2017) estimated $4.5 \%$ of adolescents to be at risk of problematic use of social media, and (Pápay et al., 2013) reported $4.6 \%$ of adolescents to be at high risk of problematic online gaming (POG) and $13.3 \%$ of adolescents to be at low risk of POG. This study is the first to report the prevalence of PIU in a cohort of 15-year-old Czech students $(M=15.3, \mathrm{SD}=0.41)$. We did not find a significant gender-based difference in the prevalence of PIU, which is usual in European adolescent samples.

The responsiveness (warmth) of mothers and fathers was negatively associated with the PIU score. Maternal and paternal responsiveness scores were significantly lower in adolescents with PIU than in those without PIU. The effect sizes were moderate. This is in line with studies reporting the negative association between IA and parent-child bonding (Bleakley, Ellithorpe, \& Romer, 2016; Casaló \& Escario, 2019; Dong et al., 2019; Shek, Zhu, \& Dou, 2019; Shek, Zhu, \& Ma, 2018; Shi, Wang, \& Zou, 2017; Siomos et al., 2012; Xiuqin et al., 2010; Xu et al., 2014). Parental strictness (behavioral control), on the other hand, showed no significant associations with PIU score. There was a higher maternal strictness in adolescents with PIU, but the effect was small. This adds even more variability to the pool of rather inconclusive results of previous studies on the effect of parental control on PIU. Parental responsiveness (warmth) seems to be a more consistent predictor of PIU than strictness (control). However, responsiveness and strictness are inseparable aspects of parental behavior. The authoritative parenting style, characterized by high 
responsiveness and high strictness, was found to be the most protective against PIU, which is in line with results obtained for other adolescent at-risk behaviors (Cablova et al., 2016; Calafat et al., 2014; Montgomery, Fisk, \& Craig, 2008). The benefits of an authoritative parenting style were shown consistently for mothers and fathers. In contrast, the least favorable parenting style with respect to PIU was different for maternal and paternal parenting. The highest incidence of PIU was found in mothers with authoritarian parenting and in fathers with neglectful parenting. This may suggest that strictness (if not accompanied by responsiveness) is more harmful in mothers than in fathers.

Some sociodemographic variables were found to influence the incidence of various parenting styles. Boys reported a significantly lower incidence of indulgent maternal and paternal parenting and a higher incidence of paternal authoritative parenting and maternal neglectful parenting. In contrast, girls showed the opposite perception of parenting styles, i.e., a higher incidence of indulgent parenting in both mothers and fathers and lower incidences of maternal neglectful parenting and paternal authoritative parenting. The intactness of the family also had an effect on parenting styles. Children from restructured families reported a higher incidence of maternal authoritarian parenting. We consider this an important finding, as this parenting style was connected with a higher risk of PIU and generally could be considered the most detrimental for children (Hosokawa \& Katsura, 2019).

We found that parental responsiveness and strictness significantly decreased during the study period, suggesting that both parental affection and control were perceived to weaken as adolescents became older. Chen, Liu, and Li (2000), who used a same-aged cohort sample of Chinese sixth-graders, also found a significant decrease in control and warmth between 12- and 14-year-olds. As we had five measurement points instead of only two as Chen et al. (2000), we could identify that this considerable decrease in control and warmth occurred during the 7 th grade (i.e., in children aged approximately 13.5 years on average).

\section{Methodological considerations}

A major strength of this population-based study was the size of the cohort of same-aged children and that we observed children prospectively. We also used reliable measurements of parental strictness (control) and responsiveness (warmth), which are widely used in other adolescent behaviors but less often in studies on PIU. Using the parent-child dyads meant higher reliability in some sociodemographic variables, e.g., family income. On the other hand, including only children whose parents were willing to participate in the study might limit the generalization of our findings to caring and responsible families. Our data came from a large-scope project that aimed to evaluate the effect of primary prevention programs focused primarily on substance use, not PIU. Therefore, PIU was not assessed within the same waves as parental behavior but instead was assessed 1.5-3.5 years later. Therefore, we measured the longitudinal effect of parenting on PIU. However, this might be seen as an advantage because longitudinal studies on the topic are scarce. On the other hand, it could be a complication for direct comparison with cross-sectional studies. Furthermore, we did not assess the possible influence of the adolescents themselves on their parents' behavior, although it is probable that the relationship was bidirectional (Kerr, Stattin, \& Özdemir, 2012). Finally, we were using the term "PIU prevalence" but were aware that PIU was assessed by a self-report screening measure and not clinically diagnosed, which might lead to overestimation of the prevalence (Maráz, Király, \& Demetrovics, 2015).

\section{Implications}

The self-reported prevalence of PIU was found to be high, which is alarming given the lack of prevention interventions focused on adolescent PIU (Vondráčková \& Gabrhelík, 2016). Parents can significantly influence internet use-related problems in their children. Authoritative style with high responsiveness and high strictness was found to be the most protective against PIU. In contrast, the combination of maternal authoritarian and paternal neglectful styles can be considered a high-risk parenting practice, with the probability of PIU reaching 20.9\%. Parents should be involved in prevention efforts and should be informed and educated by professionals about the most effective parenting styles. Special attention should also be paid to restructured families with a higher incidence of detrimental maternal authoritarian style.

\section{CONCLUSIONS}

The effects of parenting on PIU were found to be similar to those of other adolescent problematic behaviors, such as the use of alcohol, tobacco and other drugs. High parental responsiveness (warmth) seems to exert a protective effect against such behavior. The most beneficial parenting style was the authoritative parenting, which includes high responsiveness and high strictness. In contrast, the parenting styles with the highest risk of PIU were maternal authoritarian parenting and paternal neglectful parenting.

Funding sources: This study was supported by the Czech Science Foundation (Grant no. 16-15771S) and the institutional support programme of Charles University in Prague No. PROGRES-Q06.

Authors' contribution: KL had full access to all of the data in the study and takes responsibility for the integrity of the data and the accuracy of the data analysis. Concept and design: RG, KL, JV. Acquisition, analysis, or interpretation of data: KL, JV. Drafting of the manuscript: KL, RG. Critical revision of the manuscript for important intellectual content: $R G$, KL, JV. Statistical analysis: KL, JV. Obtained funding: RG. Administrative, technical, or material support: RG. Supervision: RG.

Conflict of interest: The author declares no conflict of interest. 


\section{REFERENCES}

Balogh, K. N., Mayes, L. C., \& Potenza, M. N. (2013). Risk-taking and decision-making in youth: Relationships to addiction vulnerability. Journal of Behavioral Addictions, 2(1), 1-9. https://doi.org/10.1556/JBA.2.2013.1.1.

Bányai, F., Zsila, Á., Király, O., Maraz, A., Elekes, Z., Griffiths, M. D., et al. (2017). Problematic social media use: Results from a large-scale nationally representative adolescent sample. PloS One, 12(1), e0169839. https://doi.org/10.1371/journal.pone. 0169839.

Becoña, E., Martínez, Ú., Calafat, A., Juan, M., Fernández-Hermida, J. R., \& Secades-Villa, R. (2012). Parental styles and drug use: A review. Drugs: Education, Prevention and Policy, 19(1), 1-10. https://doi.org/10.3109/09687637.2011.631060.

Bleakley, A., Ellithorpe, M., \& Romer, D. (2016). The role of parents in problematic internet use among US adolescents, Media and Communication, 24-34. https://doi.org/10.17645/mac.v4i3. 523.

Cablova, L., Csemy, L., Belacek, J., \& Miovsky, M. (2016). Parenting styles and typology of drinking among children and adolescents. Journal of Substance Use, 21(4), 381-389. https://doi.org/ 10.3109/14659891.2015.1040087.

Calafat, A., García, F., Juan, M., Becoña, E., \& Fernández-Hermida, J. R. (2014). Which parenting style is more protective against adolescent substance use? Evidence within the European context. Drug and Alcohol Dependence, 138, 185-192. https:// doi.org/10.1016/j.drugalcdep.2014.02.705.

Casaló, L. V., \& Escario, J.-J. (2019). Predictors of excessive internet use among adolescents in Spain: The relevance of the relationship between parents and their children. Computers in Human Behavior, 92, 344-351. https://doi.org/10.1016/j.chb. 2018.11.042.

Cetinkaya, L. (2019). The relationship between perceived parental control and internet addiction: A cross-sectional study among adolescents. Contemporary Educational Technology, 10(1), 5574. https://doi.org/10.30935/cet.512531.

Chen, X., Liu, M., \& Li, D. (2000). Parental warmth, control, and indulgence and their relations to adjustment in Chinese children: A longitudinal study. Journal of Family Psychology, 14(3), 401-419. https://doi.org/10.1037/0893-3200.14.3.401.

Cheng, C., \& Li, A. Y. (2014). Internet addiction prevalence and quality of (real) life: A meta-analysis of 31 nations across seven world regions. Cyberpsychology, Behavior, and Social Networking, 17(12), 755-760. https://doi.org/10.1089/cyber. 2014.0317.

Demetrovics, Z., Király, O., Koronczai, B., Griffiths, M. D., Nagygyörgy, K., Elekes, Z., et al. (2016). Psychometric properties of the problematic internet use questionnaire short-form (PIUQ-SF-6) in a nationally representative sample of adolescents. PLoS One, 11(8), e0159409. https://doi.org/10.1371/journal.pone.0159409.

Dong, B., Zhao, F., Wu, X.-S., Wang, W.-J., Li, Y.-F., Zhang, Z.-H., et al. (2019). Social anxiety may modify the relationship between internet addiction and its determining factors in Chinese adolescents. International Journal of Mental Health and Addiction, 17(6), 1508-1520. https://doi.org/10.1007/s11469018-9912-x.
Fineberg, N., Demetrovics, Z., Stein, D., Ioannidis, K., Potenza, M., Grünblatt, E., et al. (2018). Manifesto for a European research network into problematic usage of the internet. European Neuropsychopharmacology, 28(11), 1232-1246. https://doi.org/ 10.1016/j.euroneuro.2018.08.004.

Gabrhelík, R., Orosová, O., Miovský, M., Vonkova, H., Berništerová, M., \& Minařík, J. (2014). Studying the effectiveness of school-based universal prevention interventions in the Czech Republic and Slovakia. Adiktologie, 14(4), 402-408.

Honaker, J., King, G., \& Blackwell, M. (2011). Amelia II: A program for missing data. Journal of Statistical Software, 45(1), 1-47. https://doi.org/10.18637/jss.v045.i07.

Hosokawa, R., \& Katsura, T. (2019). Role of parenting style in children's behavioral problems through the transition from preschool to elementary school according to gender in Japan. International Journal of Environmental Research and Public Health, 16(1), 21. https://doi.org/10.3390/ijerph16010021.

Kerr, M., Stattin, H., \& Özdemir, M. (2012). Perceived parenting style and adolescent adjustment: Revisiting directions of effects and the role of parental knowledge. Developmental Psychology, 48(6), 1540-1553. https://doi.org/10.1037/a0027720.

Khaleque, A., \& Rohner, R. P. (2012). Pancultural associations between perceived parental acceptance and psychological adjustment of children and adults: A meta-analytic review of worldwide research. Journal of Cross-Cultural Psychology, 43(5), 784-800. https://doi.org/10.1177/0022022111406120.

Kuss, D. J., \& Billieux, J. (2017). Technological addictions: Conceptualisation, measurement, etiology and treatment. Addictive Behaviors, 64, 231-233. https://doi.org/10.1016/j.addbeh.2016. 04.005 .

Kuss, D. J., Griffiths, M. D., Karila, L., \& Billieux, J. (2014). Internet addiction: A systematic review of epidemiological research for the last decade. Current Pharmaceutical Design, 20(25), 40264052. https://doi.org/10.2174/13816128113199990617.

Li, X., Li, D., \& Newman, J. (2013). Parental behavioral and psychological control and problematic internet use among Chinese adolescents: The mediating role of self-control. Cyberpsychology, Behavior, and Social Networking, 16(6), 442-447. https:// doi.org/10.1089/cyber.2012.0293.

Maráz, A., Király, O., \& Demetrovics, Z. (2015). The diagnostic pitfalls of surveys: If you score positive on a test of addiction, you still have a good chance not to be addicted. A response to Billieux et al. 2015. Journal of Behavioral Addictions, 1-7. http://real.mtak.hu/28189/.

Montgomery, C., Fisk, J. E., \& Craig, L. (2008). The effects of perceived parenting style on the propensity for illicit drug use: The importance of parental warmth and control. Drug and Alcohol Review, 27(6), 640-649. https://doi.org/10.1080/ 09595230802392790.

Pápay, O., Urbán, R., Griffiths, M. D., Nagygyörgy, K., Farkas, J., Kökönyei, G., et al. (2013). Psychometric properties of the problematic online gaming questionnaire short-form and prevalence of problematic online gaming in a national sample of adolescents. Cyberpsychology, Behavior, and Social Networking, 16(5), 340-348. https://doi.org/10.1089/cyber.2012. 0484.

Rohner, R. P., \& Khaleque, A. (2003). Reliability and validity of the parental control scale: A meta-analysis of cross-cultural and 
intracultural studies. Journal of Cross-Cultural Psychology, 34(6), 643-649. https://doi.org/10.1177/0022022103255650.

Rohner, R. P., Khaleque, A., \& Cournoyer, D. E. (2005). Parental acceptance-rejection: Theory, methods, cross-cultural evidence, and implications. Ethos, 33(3), 299-334. https://doi.org/10. 1525/eth.2005.33.3.299.

Shek, D. T. L., Zhu, X., \& Dou, D. (2019). Influence of family processes on internet addiction among late adolescents in Hong Kong. Frontiers in Psychiatry, 10. https://doi.org/10.3389/fpsyt. 2019.00113

Shek, D. T. L., Zhu, X., \& Ma, C. M. S. (2018). The influence of parental control and parent-child relational qualities on adolescent internet addiction: A 3-year longitudinal study in Hong Kong. Frontiers in Psychology, 9, 642. https://doi.org/10. 3389/fpsyg.2018.00642.

Shi, X., Wang, J., \& Zou, H. (2017). Family functioning and Internet addiction among Chinese adolescents: The mediating roles of self-esteem and loneliness. Computers in Human Behavior, 76, 201-210. https://doi.org/10.1016/j.chb.2017.07. 028.

Siomos, K., Floros, G., Fisoun, V., Evaggelia, D., Farkonas, N., Sergentani, E., et al. (2012). Evolution of Internet addiction in Greek adolescent students over a two-year period: The impact of parental bonding. European Child \& Adolescent Psychiatry, 21(4), 211-219. https://doi.org/10.1007/s00787-012-0254-0.

Škařupová, K., Ólafsson, K., \& Blinka, L. (2015). Excessive Internet Use and its association with negative experiences: Quasi-validation of a short scale in 25 European countries. Computers in Human Behavior, 53, 118-123. https://doi.org/10.1016/j.chb. 2015.06.047.
Šmahel, D., Vondráčková, P., Blinka, L., \& Godoy-Etcheverry, S. (2009). Comparing addictive behavior on the internet in the Czech Republic, Chile and Sweden. In World Wide Internet: Changing societies, economies and cultures(pp. 544-582). University of Macau.

Twisk, J., \& de Vente, W. (2002). Attrition in longitudinal studies: How to deal with missing data. Journal of Clinical Epidemiology, 55(4), 329-337. https://doi.org/10.1016/S0895-4356(01)00476-0.

Vacek, J., Vonkova, H., \& Gabrhelík, R. (2017). A successful strategy for linking anonymous data from students' and parents' questionnaires using self-generated identification codes. Prevention Science, 18(4), 450-458. https://doi.org/10.1007/ s11121-017-0772-6.

Vondráčková, P., \& Gabrhelík, R. (2016). Prevention of internet addiction: A systematic review. Journal of Behavioral Addictions, 5(4), 568-579. https://doi.org/10.1556/2006.5.2016.085.

Wu, X.-S., Zhang, Z.-H., Zhao, F., Wang, W.-J., Li, Y.-F., Bi, L., et al. (2016). Prevalence of Internet addiction and its association with social support and other related factors among adolescents in China. Journal of Adolescence, 52, 103-111. https://doi.org/ 10.1016/j.adolescence.2016.07.012.

Xiuqin, H., Huimin, Z., Mengchen, L., Jinan, W., Ying, Z., \& Ran, T. (2010). Mental health, personality, and parental rearing styles of adolescents with internet addiction disorder. Cyberpsychology, Behavior, and Social Networking, 13(4), 401-406. https://doi.org/10.1089/cyber.2009.0222.

Xu, J., Shen, L., Yan, C., Hu, H., Yang, F., Wang, L., et al. (2014). Parent-adolescent interaction and risk of adolescent internet addiction: A population-based study in shanghai. BMC Psychiatry, 14(1), 112. https://doi.org/10.1186/1471-244X-14-112. 